\title{
Sciendo
}

Int. J. of Applied Mechanics and Engineering, 2021, vol.26, No.3, pp.198-207

DOI: 10.2478/ijame-2021-0045

\section{NUMERICAL STUDY ON DIMENSIONS AND ORIENTATION EFFECT OF SEMI-ELLIPTICAL CRACKS IN PE100 PIPELINES}

\author{
T.A. ZITOUNI ${ }^{*}$ and Z. LABED \\ Laboratory of Mechanics, Department of Mechanical Engineering, \\ University of Brothers Mentouri Constantine 1, ALGERIA \\ E-mail : tidjani.zitouni@umc.edu.dz
}

\begin{abstract}
The through-thickness crack or surface crack in PE100 pipes subjected to internal pressure represents a serious risk to the structural integrity of HDPE pipes, which has attracted wide attention in modern industry. Although experimental research offers reliable predictions of surface crack influence on pipes, the relatively high cost hinders its application. The numerical simulation, as a cost-effective alternative, has been widely applied to assess stress displacement and strain to the entire pipe structure. This is the initial approach adopted in recent decades. This article provides simulations tests of an uncracked pipe and cracked PE100 pipe under different internal pressure values, with varying each time the dimensions of the crack with $1 \mathrm{~mm}$ rate for minor and major radius and $0.5 \mathrm{~mm}$ rates for the largest contour radius, using ANSYS MECHANICAL STRUCTURAL STATIC for simulation.
\end{abstract}

Key words: pipelines, PE100, semi-elliptical crack, stress concentration, HDPE.

\section{Introduction}

A pipeline structure is subjected to complex loads because of its geometry and different duty loading conditions. The transport of the HDPE pipes requires minimal equipment and it is easy to use them on ice or in marshy areas in all field conditions HDPE pipes do not rust.

Due to manufacturing defects, mechanical component failure maybe caused by cyclic loading, and cracks may develop. It is important to have a good understanding of the mechanical behavior of polymers, as well as their mode of damage, depending on the type of loading they undergo. The durability of these structures is also an important concept to take into account when estimating their lifespan. Indeed, they are often exposed to severe environmental constraints (exposure to UV rays, chemicals, etc.), which generally lead to a modification of the very nature of the material (microstructure, physical state, chemical composition, etc.). The whole stake then rests on a realistic estimate of the lifespan of these structures, taking into account the "aging" aspect of the material which constitutes them. The difficulties associated with this type of prediction are significant because of the limited time available to the experimenter to analyze the phenomena involved. The prediction of fractures and pipe durability is important in numerous practical applications [1,2]. In most cases the surface cracking is presented in a semi-elliptic form [3,4]. In a case when a polyethylene pipe is exposed to internal pressure Benhamena et al. [5] proved that axial cracks are more harmful than circumferential cracks. On the other hand, a simulation study confirmed that the orientation of the crack gives important results (stresses, displacements, deformations) under the same initial conditions [6]. Additionally, we can figure out exactly the direction for a crack to propagate from the edge to the center point of the mesh contour (see Fig.1.)

The integrity test of the polyethylene defective (semi-elliptical crack) pipeline involves a non-linear analysis at the crack front. The finite element analysis (FEA) is an important tool to design a practical mechanical component, such as the pipelines.

\footnotetext{
${ }^{*}$ To whom correspondence should be addressed
} 
a)

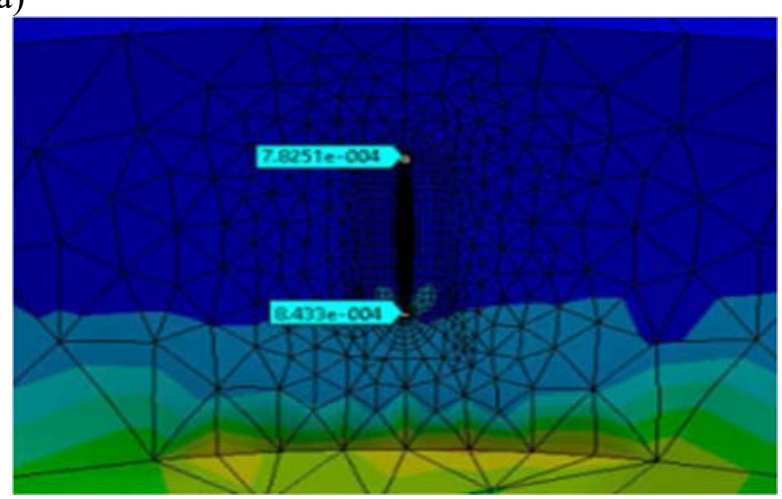

b)

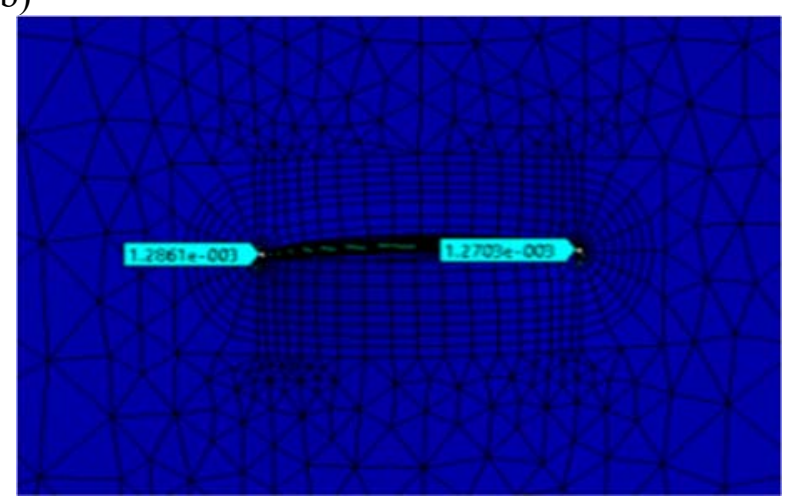

Fig.1. Displacement results: a) longitudinal crack; b) transversal crack [6].

\section{Modeling and material}

The chosen material was the third-generation high-density polyethylene (PE100). The nominal diameter and the thickness of the pipe are needed. In this paper we define a tube with an external diameter $(=63 \mathrm{~mm})$ and wall thickness $(=8.6 \mathrm{~mm})$. In Fig.2. the geometry of the structure is schematically shown with an initial defect in two different orientations.

a)

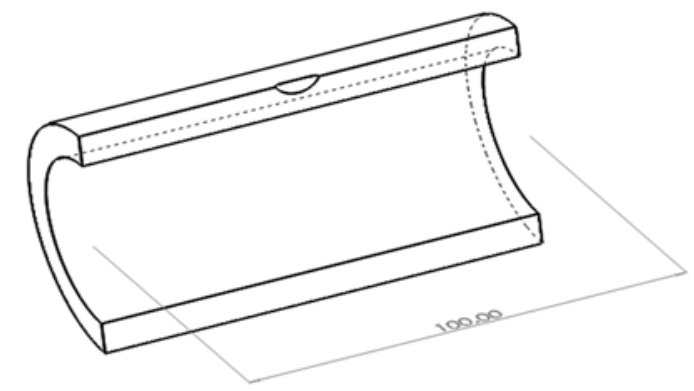

b)

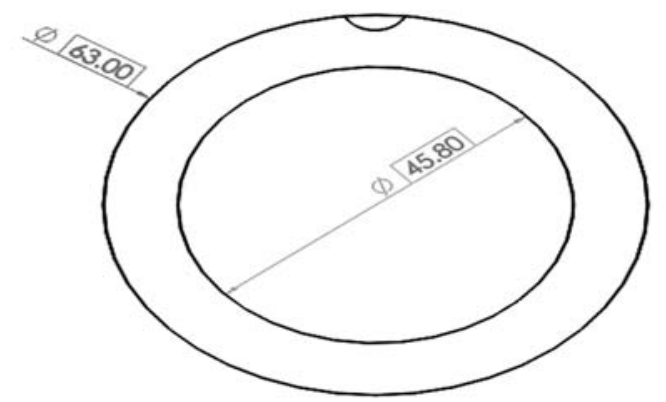

Fig.2. Pipe dimensions and crack orientation: a) transversal crack; b) longitudinal crack.

Table 1. Mechanical proprieties of PE100.

\begin{tabular}{|c|c|c|}
\hline \multicolumn{2}{|c|}{ PE100 proprieties } & References \\
\hline Young's modulus & $1000 \mathrm{MPa}$ & {$[7]$} \\
\hline Poisson ratio & 0.46 & {$[7]$} \\
\hline Tensile yield strength & $20 \mathrm{MPa}$ & {$[7]$} \\
\hline Ultimate yield strength & $34 \mathrm{MPa}$ & {$[8]$} \\
\hline
\end{tabular}

\section{Analytical study and setup}

\subsection{First case: uncracked pipe}

Based on the standards EN 12201, as well as DIN 8074/DIN 8075 and EN 13244, the next section provides various definitions used and the applicable calculations while referring to PE pipes. 


$$
\operatorname{SDR}(\text { Standard Dimension Ratio })=\frac{\text { Outside Diameter }}{\text { Wall Thickness }}=\frac{63}{8.6}=7.4
$$

According to ISO 4427, the MRS for PE100 pipe is 10.0MPa. When calculating stresses due to internal pressure, here we apply the maximum operating pressure using the SDR calculated value $(=7.4)$. This is shown in the following industrially recognized formula:

$$
M O P=\frac{(20 \times M R S)}{(C \times(S D R-1))}=\frac{(20 \times 10)}{(1.25 \times(7.4-1))}=25 \mathrm{bar}=2.5 \mathrm{MPa}
$$

where $C$ is the overall service (design) coefficient or safety factor for water applications, the minimum value of $C$ is 1.25 (in the case of our study, the fluid is water).

Next, we have to determine the stresses and deformations for the case of an internal pressure, using the following formulas which govern the radial displacement as well as the axial, radial and hoop stresses:

$$
\begin{aligned}
& u=\frac{1-\mu}{E} \cdot \frac{r_{1}^{2} P_{1}-r_{2}^{2} P_{2}}{r_{2}^{2}-r_{1}^{2}} r+\frac{1+\mu}{E} \cdot \frac{r_{1}^{2} r_{2}^{2}\left(P_{1}-P_{2}\right)}{r_{2}^{2}-r_{1}^{2}} \frac{1}{r}, \\
& \sigma_{r}=\frac{r_{1}^{2} P_{1}-r_{2}^{2} P_{2}}{r_{2}^{2}-r_{1}^{2}}-\frac{r_{1}^{2} r_{2}^{2}\left(P_{1}-P_{2}\right)}{r_{2}^{2}-r_{1}^{2}} \frac{1}{r^{2}}, \\
& \sigma_{h}=\frac{r_{1}^{2} P_{1}-r_{2}^{2} P_{2}}{r_{2}^{2}-r_{1}^{2}}+\frac{r_{1}^{2} r_{2}^{2}\left(P_{1}-P_{2}\right)}{r_{2}^{2}-r_{1}^{2}} \frac{1}{r^{2}}, \\
& \sigma_{a}=\frac{r_{1}^{2} P_{1}-r_{2}^{2} P_{2}}{r_{2}^{2}-r_{1}^{2}} .
\end{aligned}
$$

We will suppose that we do not have any external pressure so we get:

$$
\begin{aligned}
& \mathrm{u}=\frac{1-\mu}{\mathrm{E}} \cdot \frac{r_{1}^{2} P_{1}}{r_{2}^{2}-r_{1}^{2}} r+\frac{1+\mu}{\mathrm{E}} \cdot \frac{r_{1}^{2} r_{2}^{2} P_{1}}{r_{2}^{2}-r_{1}^{2}} \frac{1}{r}, \\
& \sigma_{r}=\frac{r_{1}^{2} P_{1}}{r_{2}^{2}-r_{1}^{2}}-\frac{r_{1}^{2} r_{2}^{2} P_{1}}{r_{2}^{2}-r_{1}^{2}} \frac{1}{r^{2}}, \\
& \sigma_{h}=\frac{r_{1}^{2} P_{1}}{r_{2}^{2}-r_{1}^{2}}+\frac{r_{1}^{2} r_{2}^{2} P_{1}}{r_{2}^{2}-r_{1}^{2}} \frac{1}{r^{2}} \\
& \sigma_{a}=\frac{r_{1}^{2} P_{1}}{r_{2}^{2}-r_{1}^{2}} .
\end{aligned}
$$

Von Mises's equation is: 


$$
\sigma_{v}=\frac{\sqrt{\left[\left(\sigma_{a}-\sigma_{\theta}\right)^{2}+\left(\sigma_{\theta}-\sigma_{r}\right)^{2}+\left(\sigma_{r}-\sigma_{a}\right)^{2}\right]}}{2} .
$$

\subsection{Second case: cracked pipe}

It requires defining the boundary conditions; both ends of the pipe are fixed. The automatic meshing of hexahedral elements is used, but for the crack, it is universal knowledge that tetrahedral components can combine almost every complex structure (Fig.4.). Constant internal pressure is defined by maximum operating pressure or nominal pressure (Eq.(3.2)) and applied to the structure (2.5MPa) (Fig.3).

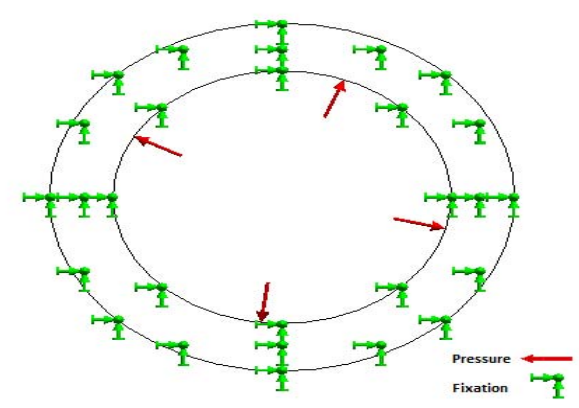

Fig.3. Section view identifying the fixed and pressured faces.

Table 2. Initial parameters of crack dimension and all possibilities

\begin{tabular}{|c|c|c|c|}
\hline & Minor radius $[\mathrm{mm}]$ & Major radius $[\mathrm{mm}]$ & Largest contour radius $[\mathrm{mm}]$ \\
\hline 1 & 2 & 3 & 0.25 \\
\hline 2 & 3 & 3 & 0.75 \\
\hline 3 & 3 & 2 & 0.25 \\
\hline 4 & 2 & 2 & 0.75 \\
\hline 5 & 2 & 2 & 0.25 \\
\hline 6 & 2 & 3 & 0.75 \\
\hline 7 & 3 & 3 & 0.25 \\
\hline 8 & 3 & 2 & 0.75 \\
\hline
\end{tabular}

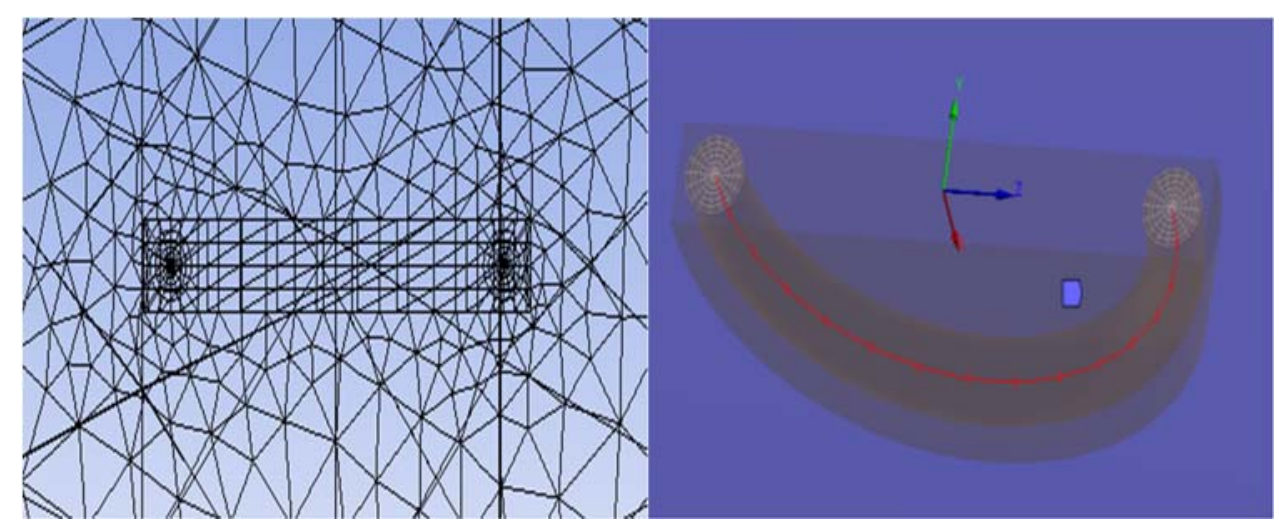

Fig.4. Tetrahedral mesh and contours presentation. 
The goal is to vary the $(M i)$ minor and $(M a)$ major radius and the (LCR) largest contour radius of the crack each time to predict which factor is more important by comparing the maximum stresses and displacements and deformations. Table 2 shows all the tested possibilities.

\section{Simulation and results}

\subsection{First case:}

Starting with the MOP value shown in Eq.(3.2) we suppose another 4 more pressure values to do the test and calculate displacements Eq.(3.7), the axial Eq.(3.10), radial Eq.(3.8) and hoop Eq.(3.9) stresses, next we try to calculate via Eq.(3.11) the von Mises equivalent stresses values for the 5, pressures applied to the internal wall of the pipe. The chosen pressure values are (2.1MPa, 2.3MPa, 2.5MPa, 2.7MPa, 2.9MPa).

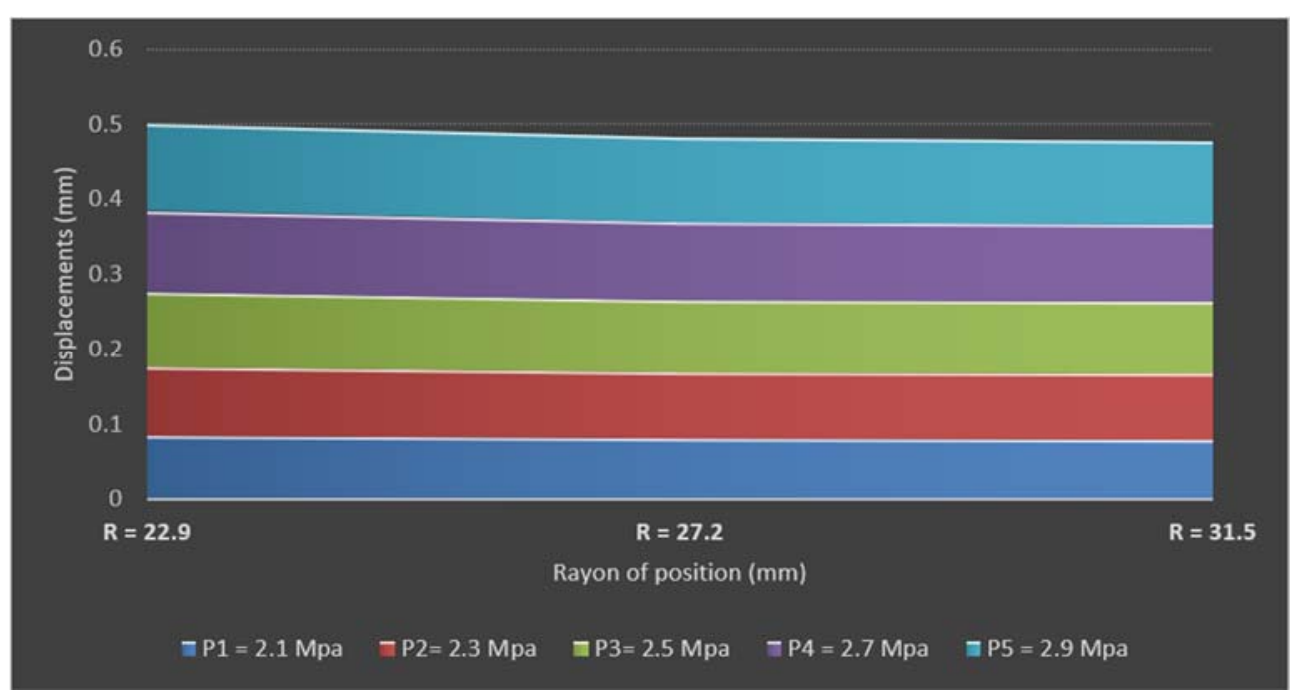

Fig.5. The maximum calculated displacements in different positions on the pipe wall.

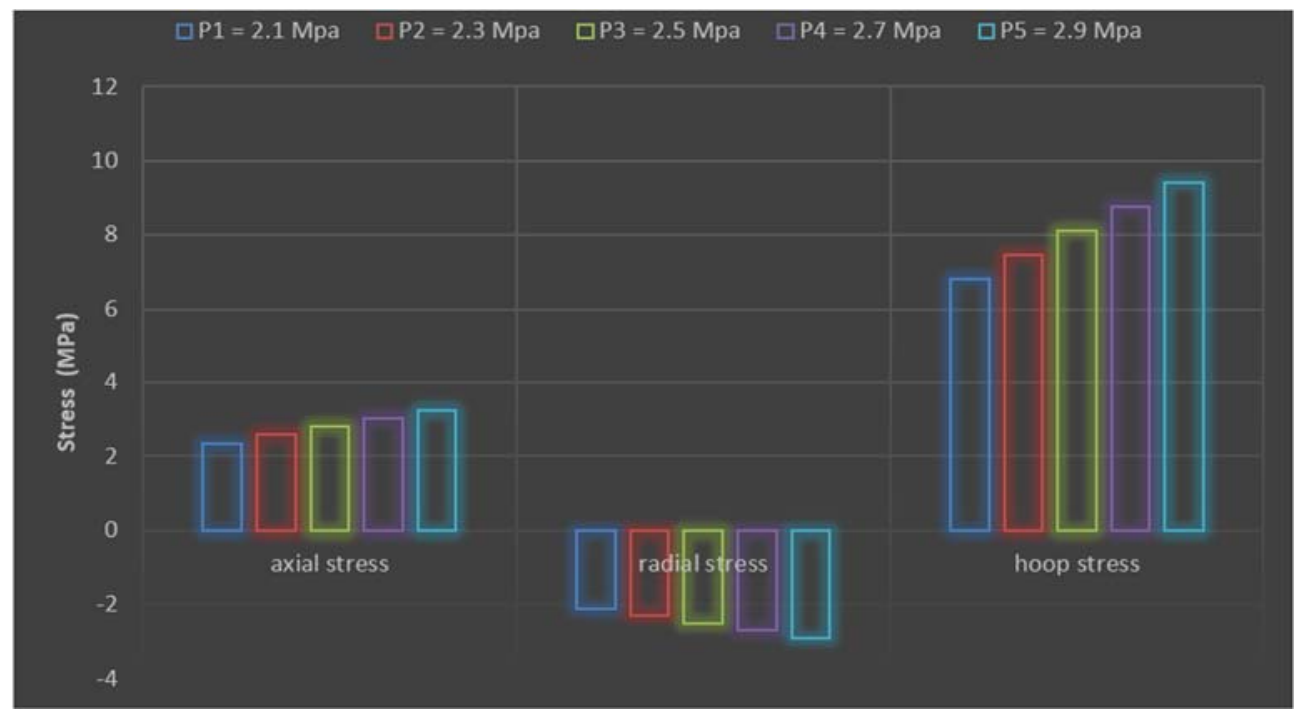

Fig.6. The calculated axial, radial and hoop stress results. 

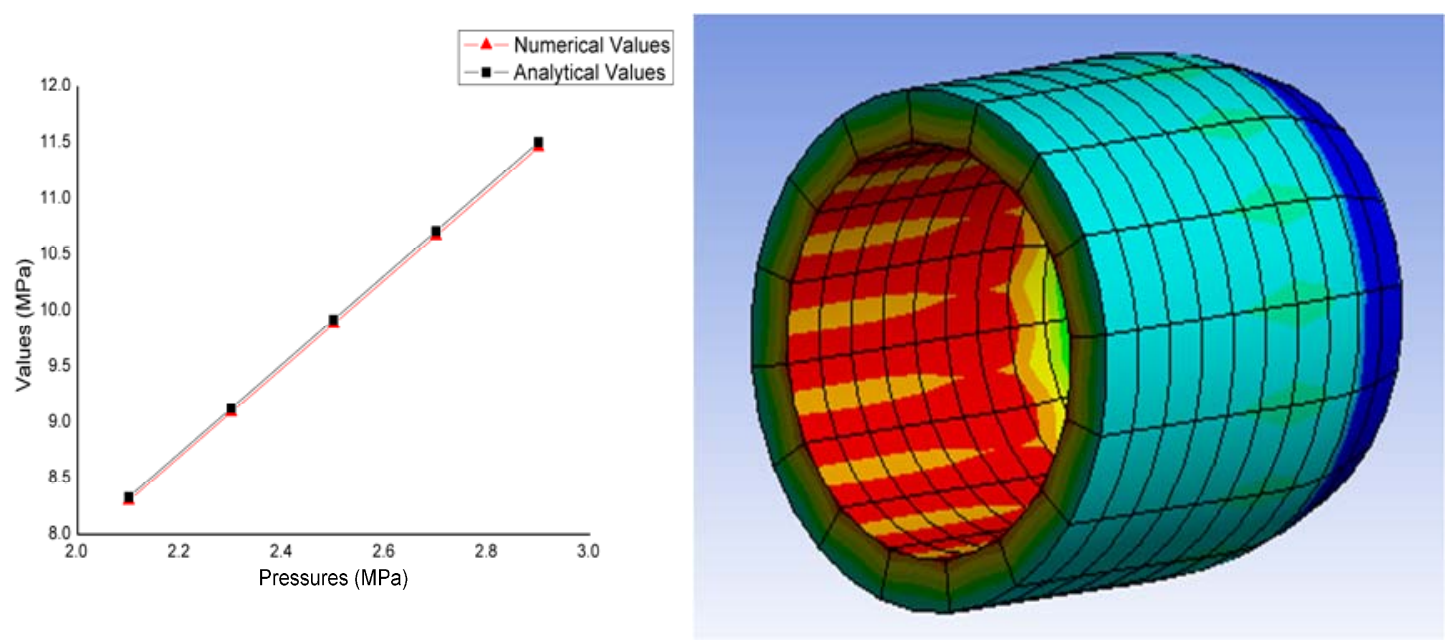

Fig.7. Numerical and analytical von Mises stress results.

Figure 5 shows that the displacement takes the highest value when it converges to the internal wall area. In other words, every augmentation in the applied pressure causes a remarkable increase in displacements.

Next, we can estimate the stresses for each of the five practical pressure values considering that $r=r_{I}$ which represents the internal wall area.

Figure 7 shows a comparative diagram of theoretical and numerical von Mises stress values, and the quadratic mesh adaption was used to calculate the von Mises stress through the maximum operating pressure $(M O P=2.5 M P a)$.

\subsection{Second case:}

In this section, we mention all the results for each case of transversal and longitudinal defect using the inverse method for optimization.

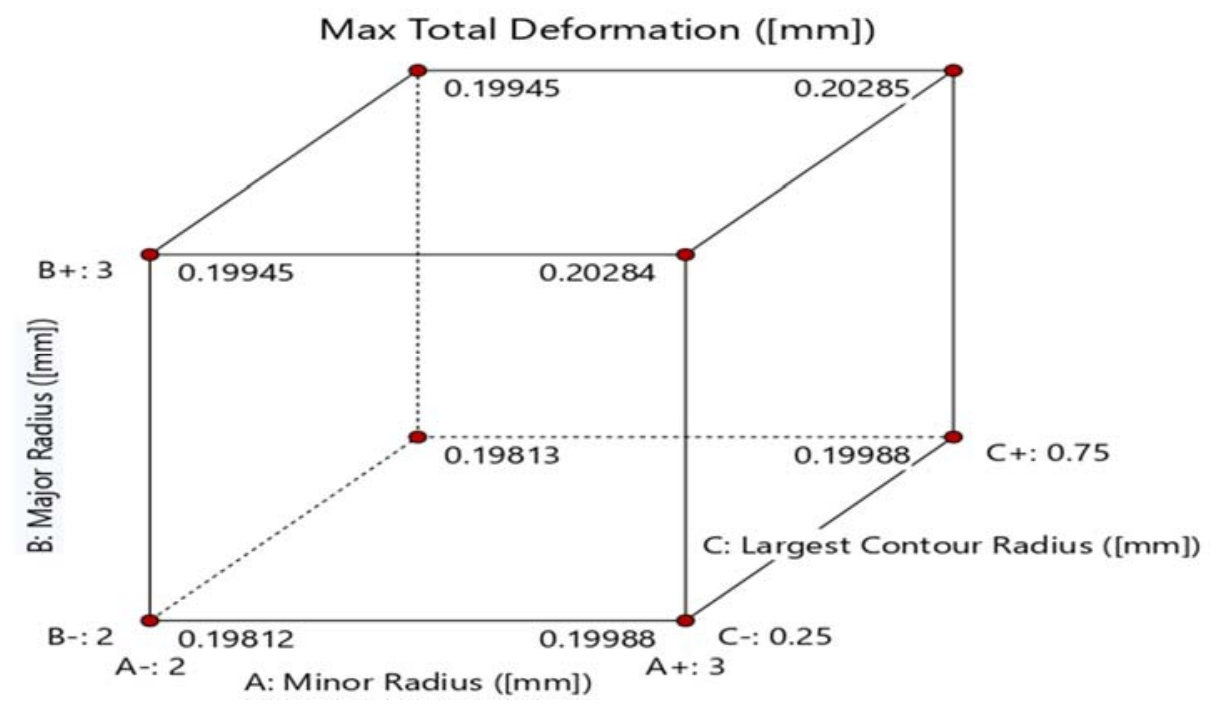

Fig.8. Maximum total displacements for a transversal crack. 
Figure 8 shows that the most dangerous case is when we have the highest minor and major radius $(M i=3 \mathrm{~mm} ; M a=3 \mathrm{~mm})$ and a maximum value of displacement $\delta$ equal to $0.20285 \mathrm{~mm}$, next we define another critical value when $(M i=3 \mathrm{~mm} ; M a=2 \mathrm{~mm})$ with maximum displacement value of $\delta=0.19988 \mathrm{~mm}$, these values are calculated for two different factors of $L C R(0.25$ and 0.75$)$ which give the same converged results.

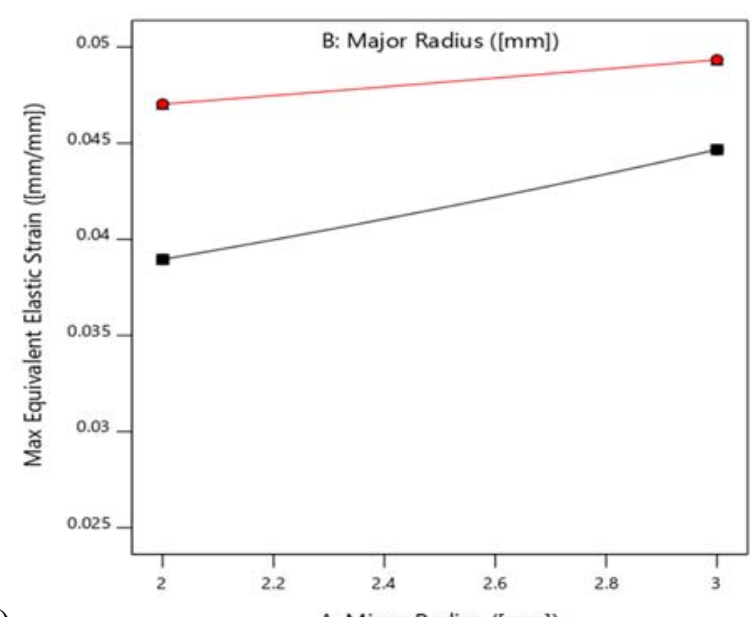

a)

Fig.9. Maximum elastic strain results for the longitu
aximum elastic strain value $\boldsymbol{\varepsilon}$ up to $0.049336 \mathrm{~mm} / \mathrm{m}$
$0.25)$, with the same dimensions just by changing the
mation $\boldsymbol{\varepsilon}$ to $0.031094 \mathrm{~mm} / \mathrm{mm}$ as shown in Fig. $9 \mathrm{~b}$.

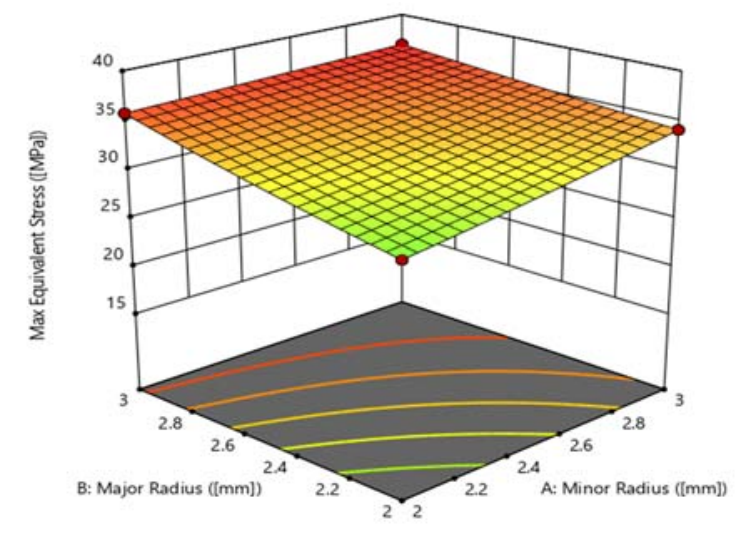

b)

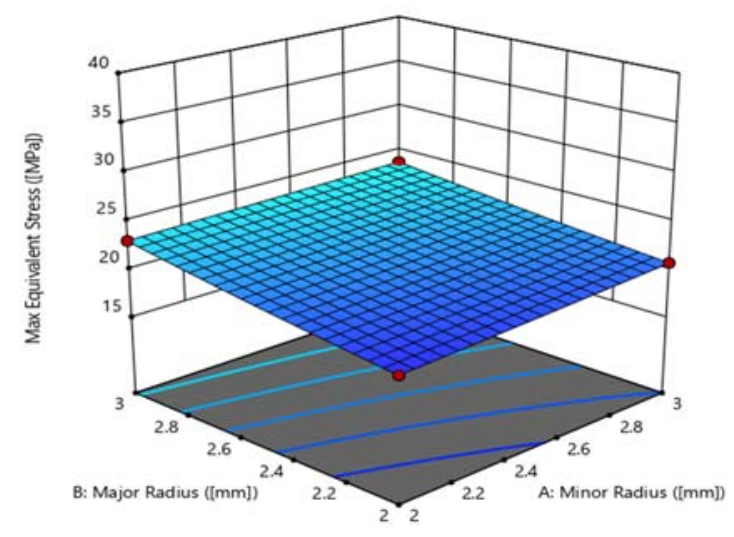

Fig.10. Maximum stress results for the transversal crack a) $L C R=0.25$; b) $L C R=0.75$.

In order to evaluate stress results, Fig.10. illustrates the effect of the $L C R$ value on the transversal crack (0.25 and 0.75). Testing all possibilities of dimension the most critical stress was observed for $(M i=M a=3 ; L C R=0.25)$ followed by the case when $(M i=2 ; M a=3 ; L C R=0.25)$ in which the critical stress was reduced to 35.8MPa. Then there is the case of $(M i=3 ; M a=2 ; L C R=0.25)$ with a max value 
equals $34.136 \mathrm{MPa}$ and the other case $(M i=2 ; M a=2 ; L C R=0.25)$, with a minimum of stress value reaching 29.687MPa.

For $L C R=0.75$ (Fig.10b) we have:

$$
\begin{aligned}
& (M i=M a=3 ; L C R=0.75)=23.677 M P a, \\
& (M i=2, M a=3 ; L C R=0.75)=23.033 M P a, \\
& (M i=3, M a=2 ; L C R=0.75)=20.717 M P a, \\
& (M i=M a=2 ; L C R=0.75)=19.265 M P a .
\end{aligned}
$$
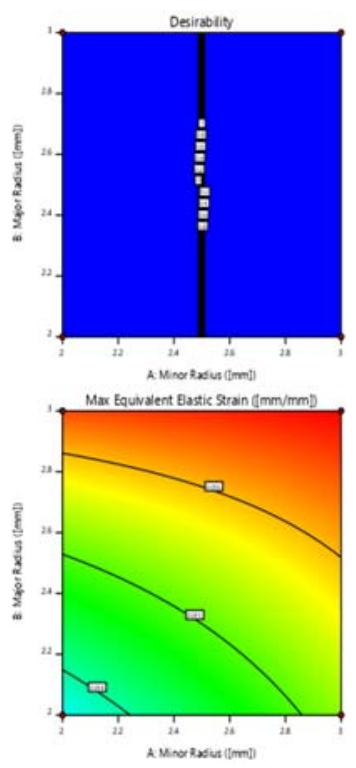
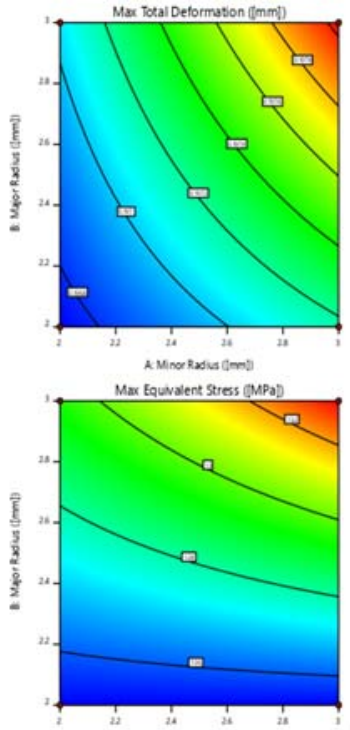

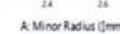
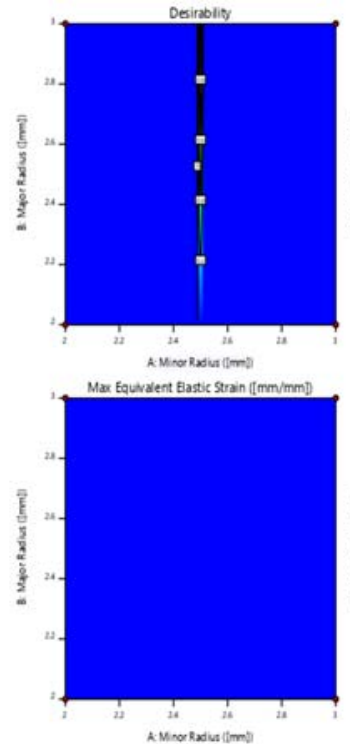

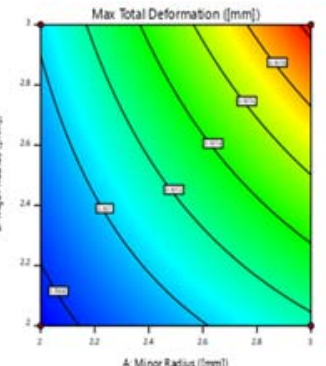

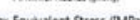

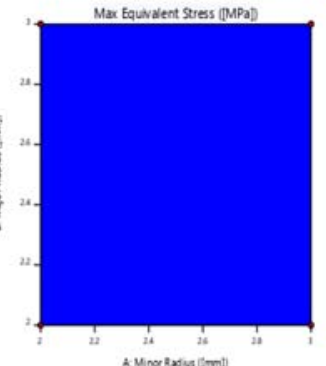

Fig.11. Results for longitudinal crack a) $L C R=0.25$; b) $L C R=0.75$.

Figure 11 shows that:

a) The red region gives the extreme values $\delta=0.19804 \mathrm{~mm}, \varepsilon=0.016767 \mathrm{~mm} / \mathrm{mm}$, and $\sigma=13.322 \mathrm{MPa}$ for $(M i=M a=3 m m)$.

b) The same figure indicates the following most critical value for $(M i=2 ; M a=3)$ with max values $\delta=0.19704 \mathrm{~mm}, \varepsilon=0.016459 \mathrm{~mm} / \mathrm{mm}$ and $\sigma=12.948 \mathrm{MPa}$.

c) A clear diminution of $\delta$, $\varepsilon$, and $\sigma$ for $(M i=M a=2)$ makes this kind of change in dimensions the safest.

For the largest contour radius $(=0.75)$ for longitudinal defect (Fig.11b.):

a) There is a disparity in deformation not in the same order as the transversal crack.

b) $(M i=3 ; M a=2)$ would be more serious than $(M i=2 ; M a=3)$ also for this situation.

c) The blue color means that $\max \sigma(=12.528 \mathrm{MPa})$ and $\varepsilon(=0.012537 \mathrm{~mm} / \mathrm{mm})$ are constant for all dimensions $(M i=3 ; M a=3),(M i=2 ; M a=3)$ and $(M i=3 ; M a=2)$. 


\section{Conclusion}

In this study, an analytical and numerical analyses were carried out on PE100 class pipe. We considered two cases, an uncracked pipe in which we applied 5 different internal pressures; in the other case, a pipe with two different orientations of crack initiation. Therefore, this is an extended work with changing randomly in each test the cracks, one longitudinal and the other transversal, varying the geometric parameters. It is about recognizing the effect of the most detrimental type of crack on the behavior of the pipe. The variation of the large radius of the contour as well as the small radius allowed us to see their effect on the behavior of the pipe. If the radius of the contour is small, the damage is greater.

The second most influential factor is the small radius for the two orientations which allowed us to observe the highest displacement, strain and stress values in the case of the transversal crack due to the circular shape of the pipe and the distribution of the internal pressure applied.

In addition, the value of the maximum stress in the case of the longitudinal crack is less than the yield strength of the material PE $100(13.322 \mathrm{MPa}<20 \mathrm{MPa})$, which is supposed to slow the propagation of the crack or stop it.

Undoubtedly, the results obtained for the transversal crack are higher than for the tensile limit $(>20 \mathrm{MPa})$ and the ultimate elastic limit $(>34 \mathrm{MPa})$ of the material with the same applied value of internal pressure $(2.5 \mathrm{MPa})$. In this case, the crack spreads more quickly. To conclude with, one can define the direction of propagation of the fracture starting from values of stresses centered on the edges of the crack which represent the centers of the contour of the mesh.

\section{Nomenclature}

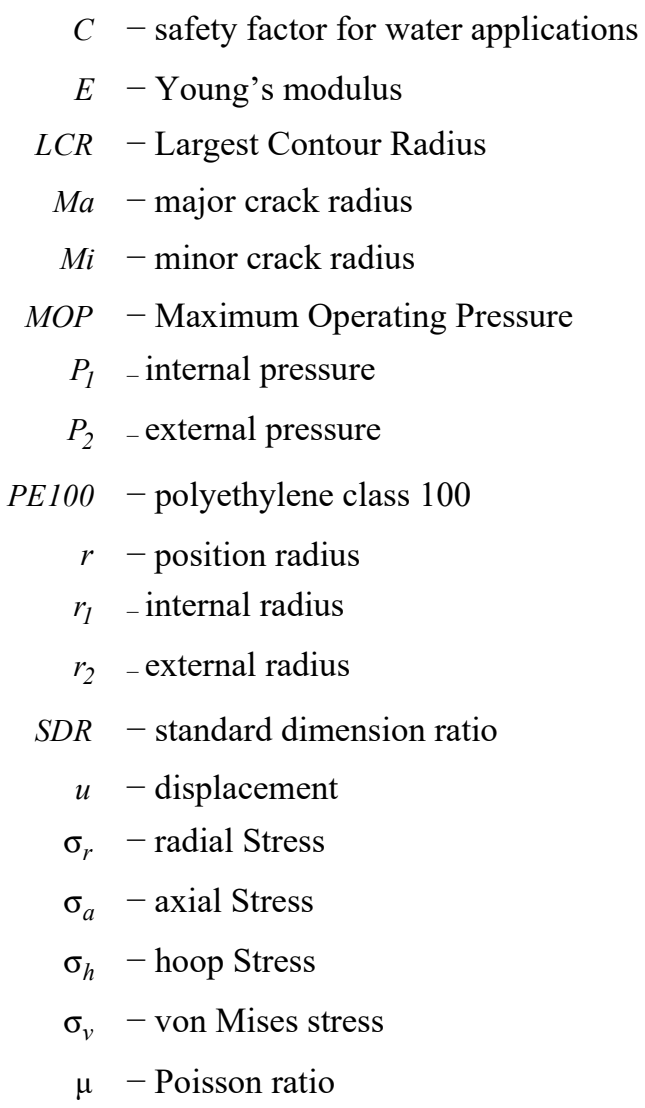




\section{References}

[1] Miller A.G. (1988): Review of limit loads of structures containing defects.- Int. J. Pres. Ves. Pip., vol.32, pp.197-327.

[2] Kim Y.J., Shim D.J., Nikbin K., Hwang S.S. and Kim J.S. (2003): Finite element based plastic limit loads for cylinders with part-through surface cracks under combined loading.- Int. J. Pres. Ves. Pip., vol.80, pp.527-540.

[3] Richard H.A. and Sander M. (2016): Fatigue Crack Growth.- Springer: Berlin, Germany.

[4] Li Z., Jiang X., Hopman H., Zhu L., Liu Z. and Tang W. (2020): Experimental investigation on FRPreinforced surface cracked steel plates subjected to cyclic tension.- Mech. Adv. Mater. Struct., DOI:10.1080/15376494.2020.1746448.

[5] Benhamena A., Bachir Bouiadjra B., Amrouche A., Mesmacque G., Benseddiq N. and Benguediab M. (2010): Three finite element analysis of semi-elliptical crack in high-density poly-ethylene pipe subjected to internal pressure.- Mater Des., vol.31, pp.3038-3043.

[6] Zitouni T.A. and Labed Z. (2019): Modeling of a crack in an internal pressure pipeline.- Proceedings of the 5th International Conference on Energy, Materials, Applied Energetics and Pollution ICEMAEP, pp.1134-1139.

[7] Alimi L., Ghabeche W., Chaoui W. and Chaoui K. (2012): Mechanical properties study in extruded HDPE80 pipe wall used for natural gas distribution.- Matériaux Tech., vol.100, pp.79-86.

[8] Ulmanu V., Draghici G. and Aluchi V. (2011): Fracture mechanics testing of high-density polyethylene (HDPE) pipe material with compact tension (CT) specimens.- J. Eng. Stud. Res., vol.17, No.3, pp.98-103.

[9] ISO I. 6259. (1997): Thermoplastic Pipes-Determination of Tensile Properties.- Part 1: General Test Method.

[10] Djebli A., Bendouba M., Aid A., Talha A., Benseddiq N. and Benguediab M. (2015): Fatigue life prediction and damage modeling of high-density polyethylene under constant and two-block loading.Procedia Eng., vol.101, pp.2-9, https://doi.org/10.1016/j.proeng.2015.02.002.

[11] Williams M.L. (1957): On the stress distribution at the base of a stationary crack.- J. Appl. Mech., vol.24, pp.109-114

[12] Chao Y.J., Liu S. and Broviak B.J. (2001): Brittle fracture: variation of fracture toughness with constraint and crack curving under mode I conditions.- Exp. Mech. vol.41, No.3, pp.232-241.

[13] Richardson D.E. and Goree J.G. (1993): Experimental verification of a new two-parameter fracture model, in Fracture Mechanics.- ASTM International, Twenty Third Symposium pp.738-750.

[14] Alimi L., Ghabeche W., Chaoui W. and Chaoui K. (2012):Mechanical properties study in extruded HDPE-80 pipe wall used for natural gas distribution.- Matériaux Tech., vol.100, pp.79-86.

[15] Ulmanu V.A, Draghici G. and Aluchi V. (2011): Fracture mechanics testing of high-density polyethylene (HDPE) pipe material with compact tension (CT) specimens.- J. Eng. Stud. Res., vol.17, No.3, pp.98-103.

[16] Engineering Toolbox (2018): EN 12201 - Polyethylene (PE) pipes for water supply, and drainage and sewerage under pressure- dimensions.- [online] Available at https://www.engineeringtoolbox.com/EN12201-PE-polyethylene-pipes-d_2135.html [Accessed 19 04. 2020].

[17] Deutsche Norm (1999): DIN 8074 - Polyethylene (PE) pipes Dimensions.- DIN German Institute for Standardization e. V., Berlin. 